\title{
Pelatihan Kebersyukuran dalam Meningkatkan Kesehatan Mental pada Ibu-Ibu Majelis Taklim di Kota Pekanbaru
}

\author{
Liliza Agustin1, Vivik Shoviah2, Yulita Kurniawati ${ }^{3}$ \\ 1,2,3Universitas Islam Negeri Sultan Syarif Kasim Riau \\ E-mail: liliza.agustin@uin-suska.ac.id
}

\begin{abstract}
Abstrak
Pengabdian ini berbasis riset dan pengembangan metode. Di latar belakangi oleh adanya upaya untuk melahirkan intervensi psikologi islami, maka peneliti mencoba merancang sebuah modul pelatihan kebersyukuran. Model pelatihan kebersyukuran merupakan intervensi psikologis teistik yang merupakan pengembangan dari model pelatihan yang diambil dari konsep syukur Ibnu Qayyim Aljauziyah. Hal yang membedakan adalah konseptualisasi dan penekanan intervensinya dalam beberapa segi. Pengembangan metode yang dilakukan adalah menggabungkan konsep Gratitude dengan syukur dalam wadah pelatihan sebagai intervensi psikologi. Harapannya, pelatihan kebersyukuran dapat diterapkan, dilakukan penelitian, dan bisa dipertimbangkan sebagai intervensi tunggal atau intervensi tambahan khususnya bagi muslim. Peserta Pelatihan Kebersyukuran adalah Ibu Majelis Taklim di Kota Pekanbaru berjumlah 20 orang.
\end{abstract}

Kata Kunci: Pelatihan kebersyukuran , Kesehatan Mental, Ibu-ibu Majelis Taklim

\begin{abstract}
Community service is based on research and method development. Against the backdrop of the effort to give birth to Islamic psychological interventions, the researcher tried to design a gratefulness training module. The gratefulness training model is a theistic psychological intervention which is the development of a training model taken from the concept of gratitude by Ibn Qayyim Aljauziyah. What distinguishes it is the conceptualization and emphasis of intervention in several ways. The method development is combining the concept of Gratitude with gratefulness in a training forum as a psychological intervention. The hope is that gratefulness training can be applied, conducted research, and can be considered as a single intervention or additional intervention, especially for Muslims. The participants of the gratefulness training were 20 people in the Taklim Council in Pekanbaru City.
\end{abstract}

Keywords: gratefulness training, Mental Health, Majelis Taklim mothers

\section{Pendahuluan}

Berdasarkan Riskesdas (2007), rata-rata nasional gangguan mental emosional ringan, seperti cemas dan depresi pada penduduk berusia 15 tahun ke atas mencapai $11,6 \%$. Sedangkan yang mengalami gangguan mental berat, seperti psikotis, skizofrenia, dan gangguan depresi berat, sebesar 0,46\%. Untuk gangguan jiwa ringan banyak diderita kaum perempuan, yaitu dua kali lebih banyak dibanding laki laki. Gangguan jiwa ringan sangat dipengaruhi oleh kondisi sosial ekonomi.

Perempuan memiliki kekhawatiran sendiri akan kesehatannya. Suatu survey yang dilakukan tahun 2016 di Australia oleh Jean Hailes for Women's Health didapatkan hasil 
bahwa kekhawatiran perempuan akan masalah kesehatan terdiri dari : Nyeri Kronis (8\%), Menopause (9\%), Masalah Kesehatan Mental (15\%), Cancer (17\%) dan Masalah Menajemen Berat Badan (23\%). Sedangkan dalam situs WebMD dikatakan bahwa kekhawatiran perempuan akan penyakit yang dialami terdiri dari masalah Jantung, Kanker Payudara, Osteoporosis, Depresi dan Penyakit Autoimun. Kedua data tersebut menyatakan juga bahwa masalah terkait dengan kesehatan perempuan selalu terkait dengan masalah mental emosional. Salah satu yang lebih sering dialami perempuan adalah Depresi.

Beberapa tahun terakhir ini, banyak terjadi kasus yang berkaitan dengan kesehatan mental perempuan terutama ibu. Baru-baru ini, tepatnya pada tanggal 21 Februari 2018 di Denpasar Bali, seorang ibu membunuh ke tiga anaknya yang diduga akibat depresi (Kumparan News, 2018). Di pekanbaru pada tanggal 18 Maret 2018, tepatnya di Kecamatan Tenayanraya, seorang ibu melakukan tindakan bunuh diri diduga akibat depresi. Di Rumbai Pesisir pada tahun 2017, seorang ibu juga melakukan tindakan bunuh diri juga diduga akibat depresi (Antara Riau, 2018).

Hal ini tentu perlu adanya tindakan agar dapat membantu perempuan terutama dalam hal ini ibu untuk meningkatkan kualitas hidupnya yang berkaitan dengan kesehatan mentalnya. Intervensi alternatif masalah kesehatan mental tersebut, maka pengabdian ini menawarkan Intervensi Psikologis berupa Pelatihan Kebersyukuran . Dikarenakan kebutuhan akan penelitian Kesehatan Mental perempuan semakin meningkat. Studi ini menyatakan bahwa terdapat hubungan yang kuat antara Kebersyukuran dengan Peningkatan Kesehatan Mental (Aziz, 2017).

Kehidupan era milineal, menjadikan perempuan semakin hari semakin disibukkan untuk memegang peranan penting di luar rumah, padahal bersamaan dengan itu mereka dituntut untuk tidak menyalahi kodratnya sebagai perempuan dalam hal masalahmasalah yang ada hubungannya dengan keluarga. Bagaimanapun tingginya perkembangan intelek dan kemampuan perempuan, baik dalam dunia pendidikan maupun dalam dunia bisnis atau bahkan menduduki posisi strategis dalam jabatan, perempuan tidak boleh begitu saja melepas tanggung jawabnya sebagai ibu rumah tangga (Depkes, 2011). Bahkan, perempuan yang hanya sebagai Ibu Rumah Tangga sekalipun juga dituntut untuk dapat memegang peranan dalam mengurusi rumah tangga dan ikut dalam membantu perekonomian keluarga.

Demikian kompleks kehidupan seorang perempuan, menyebabkan berbagai masalah kehidupan banyak dihadapinya. Adanya peran multitasking baik sebagai ibu rumah tangga dan bekerja, mengurus suami dan anak, serta faktor hormonal adalah sebagian pemicu rentannya perempuan mengalami gangguan kesehatan mental. Sangat penting untuk menjaga kesehatan mental perempuan. Untuk itulah perlu adanya upaya untuk menjaga kesehatan mental perempuan yang awalnya tentu berasal dari perempuan sendiri. Kesehatan mental menjadi faktor penting dalam menentukan kualitas hidup perempuan. Kondisi mental yang sehat mengarahkan individu untuk berusaha mencapai suatu keseimbangan dalam hidup dengan menerima kualitas positif 
dan negatif diri, menyadari potensi yang dimiliki, mampu menyesuaikan diri dengan kondisi yang sulit, serta mampu memberikan kontribusi kepada orang lain dan lingkungan.

Fenomena yang terjadi saat ini adalah kurang pedulinya masyarakat terutama perempuan pada kesehatan mental. Hal ini dikarenakan animo yang ada masyarakat, isu kesehatan mental masih menjadi isu yang jarang dibahas dalam kehidupan sosial masyarakat, padahal perempuan rentan gangguan kesehatan mental karena banyaknya peran yang dipikul dan tekanan yang mereka hadapi setiap hari. Banyak perempuanperempuan yang akhirnya diam dan abai terhadap kesehatan mental karena terlalu banyak stigma yang mengikuti isu kesehatan mental, dan tidak sedikit juga orang-orang terdekat yang malah memberikan komentar bahwa ini akibat kurangnya mendekatkan diri pada Tuhan. Bukannya membaik, hal itu malah memperburuk situasi dan mendorong sebagian orang ingin mengakhiri hidup mereka, seperti banyak kasus yang terjadi akhir-akhir ini.

Fenomena yang terjadi saat ini adalah kurang pedulinya masyarakat terutama perempuan pada kesehatan mental. Hal ini dikarenakan animo yang ada masyarakat, isu kesehatan mental masih menjadi isu yang jarang dibahas dalam kehidupan sosial masyarakat, padahal perempuan rentan gangguan kesehatan mental karena banyaknya peran yang dipikul dan tekanan yang mereka hadapi setiap hari. Banyak perempuanperempuan yang akhirnya diam dan abai terhadap kesehatan mental karena terlalu banyak stigma yang mengikuti isu kesehatan mental, dan tidak sedikit juga orang-orang terdekat yang malah memberikan komentar bahwa ini akibat kurangnya mendekatkan diri pada Tuhan. Bukannya membaik, hal itu malah memperburuk situasi dan mendorong sebagian orang ingin mengakhiri hidup mereka, seperti banyak kasus yang terjadi akhir-akhir ini.

Dari berbagai pemaparan di atas dapat diketahui bahwa perempuan banyak menghadapi berbagai sumber atau pemicu gangguan kesehatan mental. Jika hal ini tidak segera diatasi dengan baik, maka akan mengalami gangguan kesehatan mental. Melatih kebersyukuran pada karyawan terbukti efektif menurunkan stres kerja mereka (Cahyono, 2014). Emmons dan Edwards (2013) dalam penelitiannya juga menemukan bahwa orang yang bersyukur lebih efektif dalam mengatasi stres sehari-hari, memiliki resilien yang tinggi dalam menghadapi stres, lebih cepat sembuh dari penyakit, serta lebih menikmati kesahatan fisik.

\section{Metode}

Metode dalam pengabdian ini adalah intervensi psikologis berupa pelatihan kebersyukuran. Intervensi yang diberikan pada penelitian ini adalah pelatihan kebersyukuran. Pelatihan kebersyukuran ini melatih ibu-ibu majelis ta'lim agar dapat bersyukur dengan hati, lisan, dan perbuatan. Pelatihan ini dilaksanakan dalam dua kali pertemuan dalam sebelas sesi dengan total waktu 990 menit. Sebelum pelatihan dilakukan, modul intervensi kebersyukuran disusun berdasarkan aspek-aspek kebersyukuran Al-Jauziy (2010), yaitu bersyukur dengan hati, lisan, dan perbuatan. 
Modul yang telah disusun kemudian dievaluasi melalui professional judgment untuk kemudian dilakukan ujicoba.

Kegiatan ini diadakan 3 hari dengan 8 sesi pada 20 orang ibu-ibu majelis ta'lim di Kota Pekanbaru. Setiap sesi memiliki variasi waktu. Tahapan dalam kegiatan ini memasukkan nilai-nilai dalam konsep islam yaitu kebersyukuran. Kegiatan ini terdiri dari;

\section{Hari Pertama}

Sesi I

: Perkenalan

Sesi II

: Kesehatan Mental

Sesi III

: Ciri-ciri Sehat Mental

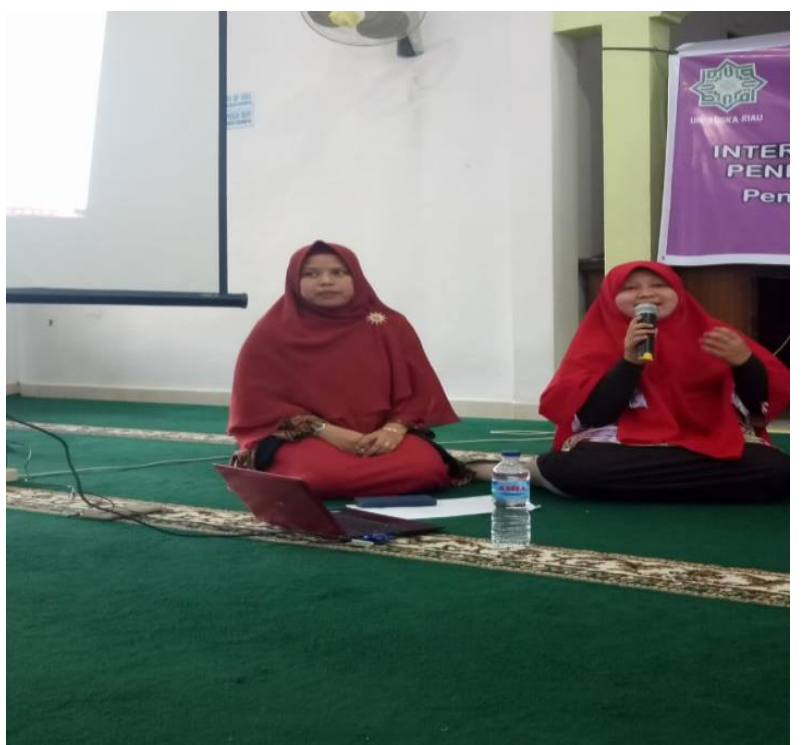

Gambar 1. Pemaparan materi hari pertama

Hari Kedua

Sesi IV : Mental yang Berpenyakit

Sesi V-VI : Kebersyukuran

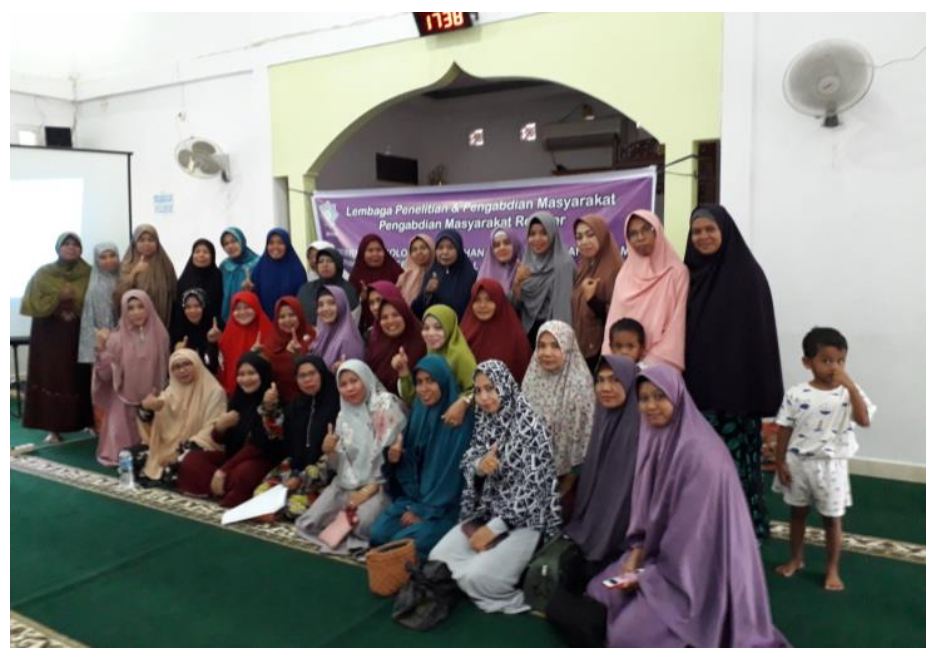

Gambar 2. Pemaparan materi hari kedua 
Hari Ketiga

Sesi VII-VIII : kebersykuran dengan sehat mental

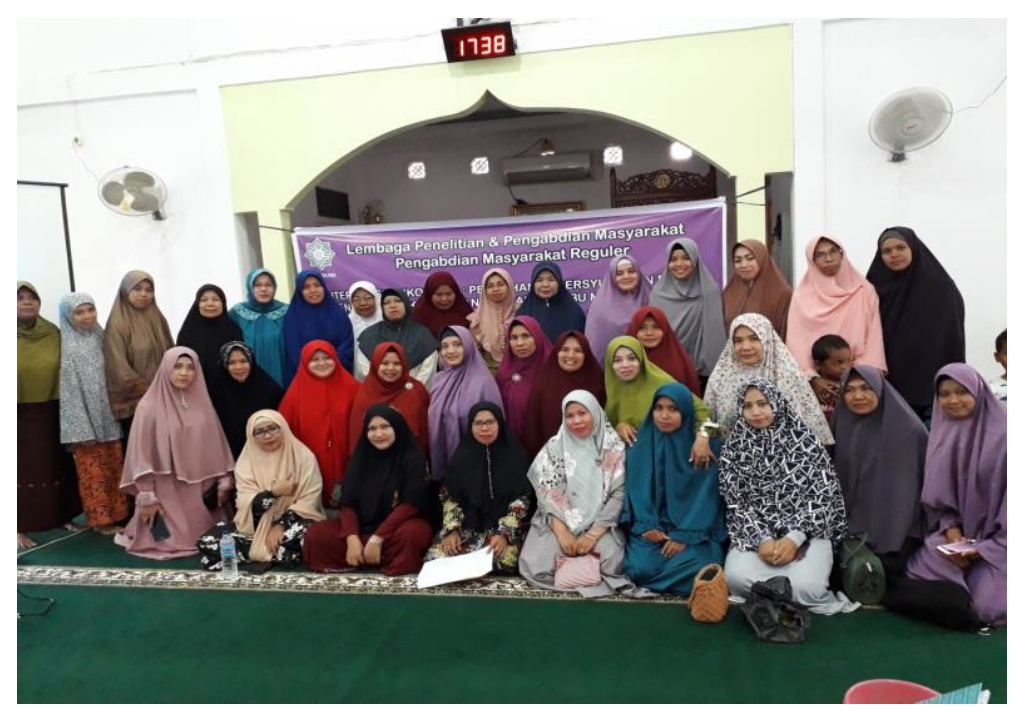

Gambar 3. Pemaparan hari ketiga.

\section{Hasil dan Pembahasan}

Sebelum upaya get in dengan guru sekolah SMK N 01 Kabupaten Siak, pengabdi melakukan riset pendahuluan sebagai penjajakan awal.Kegiatan ini dilakukan guna mengetahui kondisi dan fenomena yang terjadi di SMK N 01 Kabupaten Siak melalui obsevasi kepada Wakil Kepala Sekolah SMKN 01 Kabupaten Siak yaitu Bapak Achsin Rosidi, S.Kom.Berdasarkan observasi yang dilakukan, beliau menyatakan bahwa SMK N 01 Kabupaten Siak merupakan salah satu Sekolah Kelompok Pariwisata yang berdiri pada tahun 2013.Sekolah yang dinilai baru ini memiliki 30 Guru dimana 14 diantaranya adalah Guru PNS dan 16 diantaranya adalah guru kontrak atau non PNS. Disamping itu, guru-guru SMK N 01 Kabupaten Siak masih banyak yang baru dan muda, sehingga diperlukan ilmu pengetahuan baru untuk mengupgrade ilmu sesuai dengan perkembangan global saat ini.

Setelah melakukan pengabdian masyrakat melalui pelaksanaan intervensi psikologi berupa pelatihan kebersykuran selama 8 sesi pada 20 orang ibu-ibu majlis ta'lim yang ada di Kel. Tuah Karya, maka didapatkan hasil; 
Tabel 1. Hasil Skor Pretest dan Post test

\begin{tabular}{|c|c|c|c|c|}
\hline No & Subjek & Skor Pretest & Skor Posttest & Kategori Peningkatan \\
\hline 1 & $\mathrm{~A}$ & 74 & 145 & Sedang \\
\hline 2 & B & 75 & 160 & Tinggi \\
\hline 3 & $\mathrm{C}$ & 72 & 155 & Tinggi \\
\hline 4 & $\mathrm{D}$ & 72 & 160 & Tinggi \\
\hline 5 & $\mathrm{E}$ & 75 & 160 & Tinggi \\
\hline 6 & $\mathrm{~F}$ & 77 & 164 & Tinggi \\
\hline 7 & $\mathrm{G}$ & 78 & 108 & Sedang \\
\hline 8 & $\mathrm{H}$ & 70 & 165 & Tinggi \\
\hline 9 & I & 71 & 168 & Tinggi \\
\hline 10 & $\mathrm{~J}$ & 75 & 109 & Sedang \\
\hline 11 & $\mathrm{~K}$ & 69 & 107 & Sedang \\
\hline 12 & $\mathrm{~L}$ & 77 & 145 & Sedang \\
\hline 13 & M & 70 & 160 & Tinggi \\
\hline 14 & $\mathrm{~N}$ & 72 & 156 & Tinggi \\
\hline 15 & 0 & 74 & 140 & Sedang \\
\hline 16 & $\mathrm{P}$ & 76 & 108 & Sedang \\
\hline 17 & Q & 78 & 173 & Tinggi \\
\hline 18 & $\mathrm{R}$ & 80 & 190 & Tinggi \\
\hline 19 & $\mathrm{~S}$ & 74 & 169 & Tinggi \\
\hline 20 & $\mathrm{~T}$ & 71 & 170 & Tinggi \\
\hline
\end{tabular}

Berdasarkan hasil perbandingan pre dan post test diperoleh bahwa terjadi peningkatan skor Mental Health Inventory / kesehatan mental, hal ini menunjukkan pelatihan kebersyukuran dapat meningkatkan kesehatan mental ibu-ibu majelis ta'lim. 


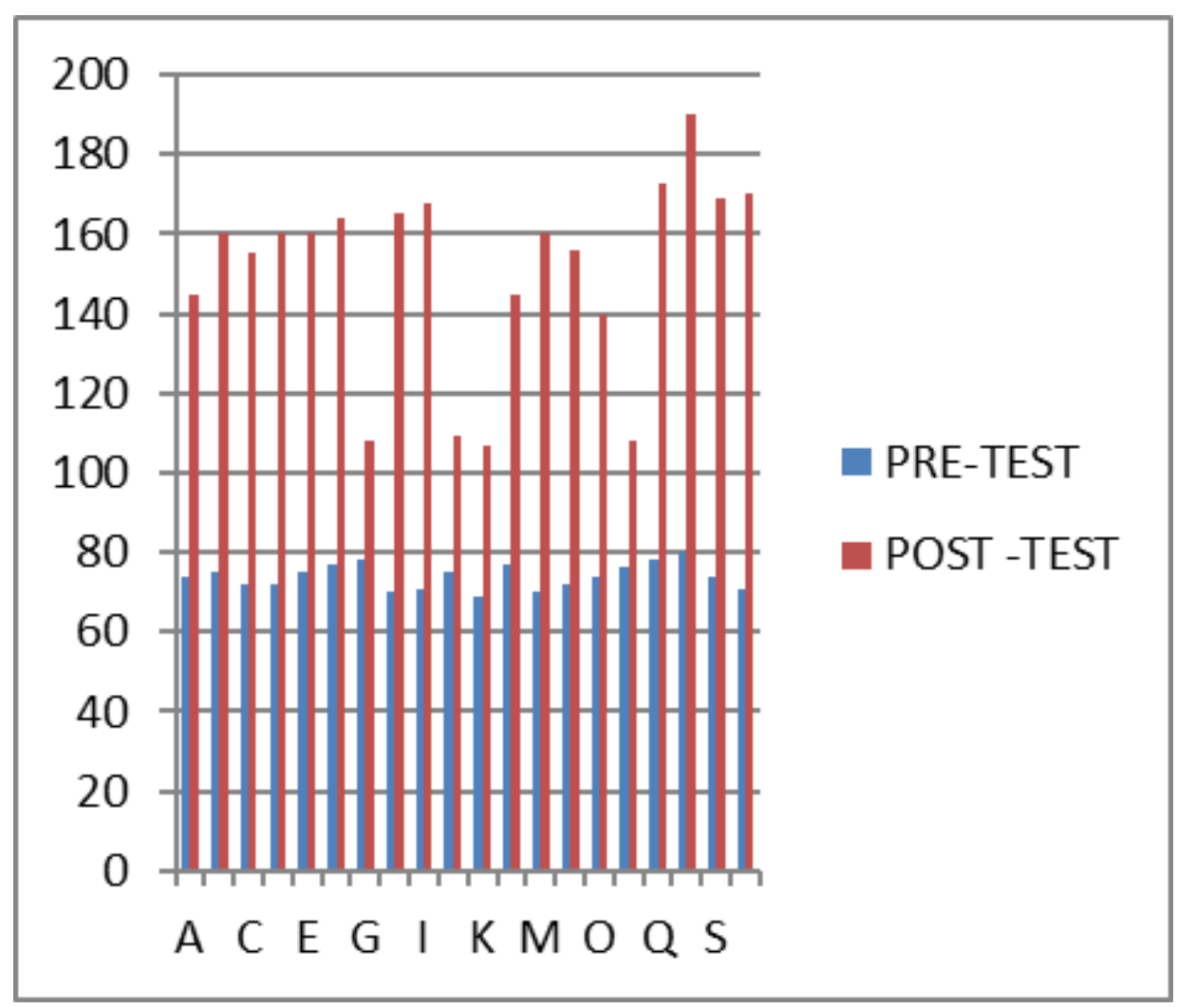

Gambar 4. Grafik Pre dan Post test

Bersyukur menumbuhkan pengalaman hidup yang positif dari pengalaman hidup atausituasi yang dihadapi, sehingga seseorang dapat mengeluarkan kepuasan secara maksimal dan menikmati keadaan mereka. Bersyukur juga merupakan strategi koping. Dalam bersyukur seseorang menafsirkan secara positif permasalahan hidup (Arief \& Habibah, 2015). Berterima kasih atas kehidupan dapat menimbulkan ketenangan pikiran, kebahagiaan, kesehatan fisik, dan hubungan pribadi lebih memuaskan (Emmons \& McCullough, 2003). Sesuai dengan penelitian Froh, Seffick, dan Emmons (2008) diketahui bahwa pandangan kebersyukuran tidak memerlukan kehidupan yang penuh kenyamanan materi melainkan sikap interior bersyukur terlepas dari kondisi kehidupan.

Islam telah menjelaskan konsep bersyukur secara detail. Berdasarkan studi literatur, syukur adalah rida atas nikmat Allah dan beramal atasnya. Syukur yang berbentuk rida dengan hati dan mengetahui dengan ilmu (ma'rifah al-ni'mah) merupakan dimensi internal dari bersyukur (al-shukr al-dākhiliah). Tidak cukup dikatakan bersyukur tanpa adanya respon berupa tindakan eksternal (al-shukr alkhārijiyah) baik secara lisan maupun perbuatan. 
Liliza Agustin, Vivik Shoviah, Yulita Kurniawati Pelatihan Kebersyukuran Dalam Meningkatkan Kesehatan Mental Pada Ibu-lbu Majelis Taklim di Kota Pekanbaru

\section{Simpulan}

Simpulan yang dapat diambil dalam pengabdian masyarakat ini adalah adanya perubahan skor Mental Health Inventory/ kesehatan mental. Pentingnya kebersyukuran dan pemahaman bagaimana cara bersyukur yang diajarkan dalam konsep islam dapat mengubah tingkat kesehatan mental ibu-ibu majelis ta'lim.

\section{Referensi}

Al-Jauziyyah, I. Q. (2010). Sabar dan syukur: Menguak rahasia di balik keutamaan sabar dan syukur. Semarang: Pustaka Nuun

Al-Munajjid, M. B. S. (2006). Silisilah amalan hati: Ikhlas, tawakkal, optimis, takut, bersyukur, ridha, sabar, introspeksi diri, tafakkur, mahabbah, taqwa, wara'. Bandung: Irsy

Arief, M. F., \& Habibah, N. (2015). Pengaruh Strategi Aktivitas (Bersyukur dan Optimis) terhadap Peningkatan Kebahagiaan pada Mahasiswa S1 Pendidikan Guru Sekolah Dasar. Seminar Psikologi dan Kemanusiaan

Arrofiq, A. (2013). Makna Syukur Guru Tidak Tetap pada Sekolah Dasar Muhammadiyah di Surakarta. Naskah Publikasi Psikologi dan Pendidikan Agama Islam Universitas Muhammadiyah Surakarta.

Aziz, R., (2015), Aplikasi model Rasch dalam pengujian alat ukur kesehatan mental di tempat kerja.Psikoislamika,12(2).1-16.

Bartlett, M. Y., \& DeSteno, D. (2006). Gratitude and prosocial behavior: Helping when it costs

you. Psychological Science, 17(4)

Bono, G., Emmons, R. A., \& McCullough, M. E. (2004). Gratitude in practice and the practice

gratitude. Positive Psychology in Practice, 464-481. Departemen Agama RI, (2002). Al-Qur'an dan Terjemahannya. Jakarta:Darus Sunnah.

Chadha, M., \& Pandey, N. (2015). A Study of Quality of Life among Government and NonGovernment Secondary School Teachers. Indian Journal of Health and Wellbeing. 6(1), 37-41.

Chan, D. W. (2010). Teacher Burnout Revisited: Introducing Positive Intervention Approaches Based on Gratitude ad Forgiveness. Educational Research Journal. 25(2).

Damasio, B. F., Melo, R. L. P., \& Siva, J. P. (2013). Meaning in Life, Psychological WellBeing and Quality of Life in Teachers. Paideia. 23(54), 73-82.

Emmons, R. A., \& McCullough, M. E. (2003). Counting Blessings Versus Burdens: An Experimental Investigation of Gratitude and Subjective 38

McCullough, M. E., Emmons, R. A., \& Tsang, J. A. (2002). The grateful disposition: A conceptual and empirical topography. Journal of Personality and Social Psychology, 82, (1), 112-127. 
McCullough, M. E., Tsang, J. -A., \& Emmons, R. A. (2004). Gratitude in intermediate affective terrain: Links of grateful moods to individual differences and daily emotional experience. Journal of Personality and Social Psychology, 86, (2), 295309. 